\title{
SOCIOLINGUISTICS
}

\section{Multilingualism: Sociolinguistic Aspect}

\author{
O. Opanasenko, A. Malii \\ Kyiv National Taras Shevchenko University, Kyiv, Ukraine \\ Corresponding author. E-mail: astmaliy@gmail.com
}

Paper received 29.11.19; Accepted for publication 23.12.19.

\section{https://doi.org/10.31174/SEND-HS2020-223VIII37-09}

\begin{abstract}
The article is devoted to the study of preconditions and peculiarities of functioning and the consequences of a phenomenon, spread in many contemporary countries, particularly Germany, called multilingualism.

Keywords: multilingualism, globalization, social mobility, linguistic diversity, foreign language proficiency.
\end{abstract}

Inroduction. The topic of the article is the phenomenon of multilingualism [1], which in the age of globalization is of a regular nature in most countries of Western Europe, first of all Germany, which has become a "haven" for millions of refugees from the East. The purpose is to investigate the causes and consequences of multilingualism in society and to show how this task is being solved in German society. In the conclusions, I make small recommendations to countries that, for various reasons, too, primarily the influx of migrant workers, face the same problem. which became a "haven" for millions of refugees from the East. The purpose is to investigate the causes and consequences of multilingualism in society and to show how this task is being solved in German society. The conclusions make small recommendations to countries, which, for various reasons, are primarily the influx of migrant workers facing the same problem.

The purpose of this brief exploration is the need to investigate the causes of multilingualism, the consequences of its spread and development. For example, Germany is considered to be one of the multilingual states. The basic material for this study is the statistics presented on the website of the Ministry of the Interior of Germany and the Federal Agency for Migrants and Refugees (VAMF), the Federal Ministry of Education and Research (BMBF) and the European Commission on Integration are provided. Historical and quantitative research methods will help to do a little exploration and give an idea of this phenomenon in German society. Consideration of the issue from different angles (vertically in the historical section and horizontally in the geopolitical and sociological) will give an objective assessment and bring the definition of "multilingualism" closer to understanding.

Results. Among the historical factors behind multilingualism is the main reformatting of political forces in Europe in the late 1980s and early 1990s brought to the arena new European countries that declared democracy as their national value. Yes, Eastern Europe was given the long-awaited freedom instead of the socialist regime. Subsequently, accession to the European Union and free movement within it caused a large migration flow. During this same period, Germany, feeling responsible for maintaining peace and democracy in Europe, pursued a policy of returning to its historical homeland the ethnic Germans and German immigrants.

In the context of history, we are reminded of globalization, which has started many new things. Global process- es, which are observed in all spheres of life, are gaining momentum and imposing increasing demands on humanity. Today, a person who is fluent in a foreign language and uses it as a tool in acquiring new knowledge is not unique. The world has been united in social networks, thus making it easier to communicate at the interstate level. Globalization and development of modern information technologies. causing social mobility are the main causes of multilingualism. Mobility is the result of overcrowded European universities and a multinational "army" of workers. The next fateful events in the world were political and geopolitical transformations (wars, etc.). When the flow of migrants and emigrants found themselves at the "door" of developed European countries, the need to help them integrate, even temporarily, into a society in which they found their refuge, became a major national task.

At the same time as historical changes, geopolitical changes take place - almost all Eastern European countries during 1995-2007. they are part of the European Union and are subordinate to a single European Commission. Therefore, the European Union's "multilingualism" course becomes an integral part of these countries' internal policies. [2] The second factor, geopolitical, is more powerful and long-lasting than the historical one, as the program to introduce "the use of a variety of languages within the European Union: native, English and the language of its nearest neighbor", started in the early 2000s, has not ceased. but on the contrary, they diversify and refine.

1.

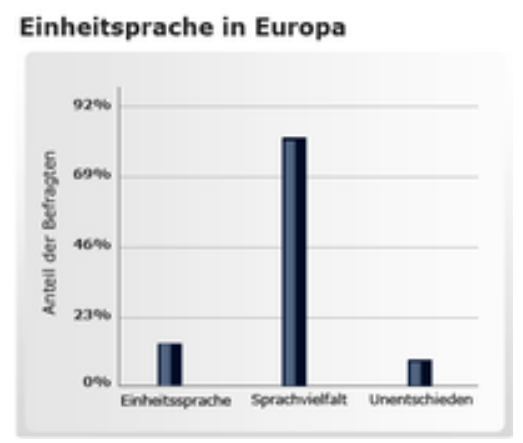

By definition of "multilingualism" is assumed to be more than two foreign languages. The Europeans themselves testify to the 2008 poll. in the target group "high school students of EU countries studying in secondary schools". Statistics show an increase in "for" indicators: 
out of 1820 respondents from 16 years, $78 \%$ said "multilingualism" and "variety of languages". in English [3 Statistik am 13. June 2008 durch IfD Allensbach.]

The older generation (roughly the age of their parents of 40 years) is of the same opinion: they believe that knowledge of a variety of foreign languages is a necessary component of modern Europe. Thus, $63 \%$ of Germans speak and understand English well (98\% of school children), but unfortunately only $18 \%$ (38\% of children) speak and speak French, although it is a subject in many schools. This is why generation-parents are paying much attention to this issue and want their children to learn as many foreign languages as possible at school. The survey on the needs of multilingualism indicated the need for knowledge of English by all scientists and professionals in the technical professions. Other spheres of life may be in one common mother tongue. However, the saturation of every language by Anglo-Cyzisms in any case dictates the need to speak one. [4]

The democratic forces of society also insist on linguistic diversity. Germany's choice is multilingualism. Therefore, it is quite natural statistics of world tourism: $40 \%$ of Germans-traveling the world is overwhelming majority among other foreigners who feel at home quite comfortably due to free communication and lack of a language barrier. By itself, the country is becoming more attractive to those who drive, thanks to the ability of the Germans to speak fluent foreign languages. However, multilingualism is not a new phenomenon in German language until recently in a monolingual society. According to linguistic researchers, knowing many languages among Germans has been relevant for 50 years. At a conference in Dortmund [5] (October 2011) on the subject, it was about language education and foreign language acquisition at different levels (from kindergarten to university). All target groups were covered for analysis. Issues for the discussion were opportunities for transition from kindergartens to schools with a multilingual audience, and support, as well as support from parents in the family for child adaptation and self-adaptation. Media projects in schools have been proposed for consideration. Foreign language learning programs for students with migrant backgrounds were discussed. ProDaZ - German as a Second Language in All Specialties at Duisburg-Essen University and Echte Väter (Real Daddy) Jobs in the Regions to Promote and Support Children from Emigrant Families were presented and approved as work-related projects. (RAA) and Herne. The latest project was aimed at fathers from Turkish families who were to become role models for their children in the family. Other issues addressed were the influence of German on the mother tongue: the replacement of some Italian words with German and vice versa (Maria Costa, Bochum University). The flip side of the multilingualism of the younger generation is the misunderstanding of parents in the family. This is not just a misunderstanding of German, but the mother tongue (Turkish, Arabic) has also changed so that the language barrier in families with a migratory background becomes more and more frequent. [6]

Multinational Germany from 2006 to 2015 9,107,893 foreigners received an increase, of which the three largest groups were Turks 1,506,113, Poles 740,962 and Italians596,127. [7] Thus, tolerance policy in the European
Union and, above all, in Germany, is becoming a guiding vector in society. Multilingualism is becoming a top priority in European politics.

The phenomenon of multilingualism in the state can be forced and deliberately acquired. Forced multilingualism is observed in countries whose development is higher than average, so they may be attractive in terms of labor migration (within the European Union) and emigration (from non-EU countries to such). These are, first of all, Germany, the Netherlands, Denmark, France and the United Kingdom, who have provided jobs to citizens of Poland, Hungary, Romania and Bulgaria. In the conditions of migration of the state of the countries - "employers" begin the state program on studying the language of the country with "emphasis" on professional activity. For example, the German Institute for German Economics (InstitutderdeutschenWirtschaftKöln), the GrundbildungfürdenArbeitsplatz program, started in Germany in 2012 [8]. This project started 4 years ago and today has a network of educational centers across Germany - from South to North. Every day, 4.3 million low-skilled workers face the realities of everyday life: completing work contracts, communicating in the workplace, and integrating into society. Increasing technical capabilities are increasing workforce requirements. Therefore, the interest of the employer is obvious, therefore, the state is directly interested in this. The AlphaGrund project (Arbeitsplatzorientierte Alphabetisierung und Grundbildung Erwachsener) provides free offers of various qualifications directly at the enterprises, "adjusting" to the work schedule and the individual needs of each classification. The project is supported and funded by the Federal Ministry of Education and Research [8]. The implications of these costs are obvious. As a result, the short, calculated max. During 10 weeks of training, trainee students are able to save money on error correction by professionals (now they can do it on their own), improve skills (due to better understanding with management), as a consequence of avoiding, or at least reducing, industrial accidents, promotion motivation and interest in work, increasing flexibility in moving workers and replacing them with others, improving internal and external communication.

Deliberately acquired multilingualism is a European Union course on understanding between peoples and cultures, a course on tolerance and mobility, which is an integral part of the "creation" of the European Union. In 2005 and 2007. The European Commission conducted surveys among EU citizens (25 EU Member States plus Bulgaria, Romania, Turkey and Croatia. Bulgaria and Romania joined the EU in 2007.) [9] Comparisons between the surveys show some changes over the two years. Survey data based on a sufficiently broad study were taken as a basis: not only age differences but also the year of secondary and higher education were taken into account; type of activity, social position; data on acquired foreign language skills; number of foreign languages spoken by the respondent, etc.

In the context of our study, the following data may be interesting:

- The most commonly used native language within the EU is German (16\%), followed by English (13\%), French (12\%) followed by Spanish and Polish $(8 \%)$

- $54 \%$ of EU citizens speak at least one foreign lan- 
guage; $25 \%$ in two languages and $10 \%$ in three.

- The following countries have high foreign language proficiency: Luxembourg (98\%), Latvia (95\%), the Netherlands (94\%), Malta (93\%). They are followed by Slovenia, Lithuania $(92 \%)$

- German and Russian have become the most popular foreign languages in the EU since 2005.

The majority of European citizens consider their level of foreign language proficiency sufficient: (44\% watch television and listen to radio in a foreign language; $45 \%$ read newspapers and magazines in a foreign language; $39 \%$ use the language to communicate online in social networks - among them speak English 26\%, German and French 5\%). English remains \# 1 among communication languages. As the situation has changed in recent years, the Eurobarometer, which conducts sociological surveys, has shown us a statistical analysis. So, let's compare the survey data for 2005, 2007, 2012. At the beginning of the study period, $37 \%$ of respondents watched foreign language television, $25 \%$ used the internet daily, $36 \%$ communicated in a foreign language, $27 \%$ used a foreign language during work, $50 \%$ spoke during holidays and vacations. For 2007. there was a corresponding increase of $+10 \%$ - watching $\mathrm{TV}$ and listening to the radio, $+8 \%$ communicating online, but $-4 \%$ communicating at work and on vacation (a decrease from 50\% in 2005, 13\% in $2007,9 \%$ in 2012)..) The percentage of foreign language users decreased daily - $23 \%$ consider themselves to be inactive users. However, the level of awareness of foreign languages among EU citizens is quite high: $88 \%$ believe that at least one foreign language should be spoken in addition to the mother tongue; $67 \%$ are convinced that English is very important to them; accordingly, $17 \%$ consider German to be important (10\% in 2012); $16 \%$ French (in 2012 - 9\%); 14\% - Spanish and 6\% - Chinese (12\% in 2012!) [9] These changes are explained by the deployment of forces in the world market and the expansion of Chinese capital.

Conclusions. Thus, despite its diminished interest in language learning, Germany remains today the most multicultural and multilingual state, attractive to migrant flows and refugee armies. Respecting democracy, and being tolerant of all nationalities and religions, it leaves no doubt about its hospitality. Therefore, there is a need for further implementation of multilingualism policy in the EU countries and, above all, in Germany.

\section{REFERENCE}

1. https://uk.wikipedia.org/wiki/Mehsprachigkeit.

2. Die europäischen Bürger und ihre Sprachen http://ec.europa.eu/eurostat/statisticsexplained/index.php/Category:Alphabetical_index/de.

3. Welche Sprache(n) soll(en) gelehrt werden? http://ec.europa.eu/eurostat/statisticsexplained/index.php/Category:Alphabetical_index/de

4. Die europäischen Bürger und ihre Sprachen http://ec.europa.eu/eurostat/statisticsexplained/index.php/Category:Alphabetical_index/de

5. SomehrsprachigistDeutschland - nach 50 JahrenMigration http://home.edo.tu-

dortmund.de/ hoffmann/PDF/Tag_Programm28_09_11.pdf
6. SomehrsprachigistDeutschland - nach 50 JahrenMigration http://home.edo.tudortmund.de/ hoffmann/PDF/Tag_Programm28_09_11.pdf

7. Anzahl der Ausländer in Deutschland nach Herkunftsland in den Jahren 2014 und 2015 https://de.statista.com/themen/46/einwanderung/)

8. Arbeitsplatzorientierte Alphabetisierung und Grundbildung ErwachsenerBundesministerium für Bildung und Forschung (BMBF) http://www.alphagrund-projekt.de/

9. Die europäischen Bürger und ihre Sprachen http://ec.europa.eu/dgs/education_culture/repository/language s/policy/strategic-framework/documents/ebs_386_de.pdf 